Gerontology 1990;36:248

\title{
Announcement
}

\section{Preliminary Announcement}

Second International Springfield Symposium on Advances in Alzheimer Therapy The Relation of the Cholinergic System to the Therapy of Alzheimer Disease Organizers: Robert Becker, MD and Ezio Giacobini, MD, PhD May 3-5, 1991, Springfield, Ill., USA

The meeting focuses on three promising approaches: the use of cholinesterase inhibitors, cholinergic agonists and nerve growth factor. New clinical data from the use of THA, metrifonate, heptylphyso-stigmine and other new drugs in Alzheimer disease patients will be presented.

Further announcements and call for abstracts will follow.

If you would like to receive more detailed information about this meeting, please return the enclosed card.

Direct correspondence to:

Ms. Ann Ogden, Office of Continuing Education Southern Illinois University School of Medicine PO Box 19230, Springfield, IL 62794-9230 (USA) Telephone: 217-785-4414; Fax: 217-782-0988 